\title{
Study of the influence of hot water consumption pattern on SHW systems under solar Spanish regulation compliance using TRNSYS
}

\author{
E. Massaguer ${ }^{1}$, L. Montoro ${ }^{1}$, A. Massaguer ${ }^{1}$, A. Deltell ${ }^{1}$ and S. Lorenz ${ }^{2}$ \\ ${ }^{1}$ Department of Mechanical Engineering and Industrial Construction \\ Polytechnic High School, University of Girona \\ Campus de Montilivi, 17071 Girona (Spain) \\ Phone/Fax number:+0034 972 419654, e-mail: eduard.massaguer@udg.edu \\ ${ }^{2}$ Local Energy Agency of Murcia ALEM \\ Plaza Robert Schuman, s/n 30007, Murcia, Spain. \\ Phone/Fax number:+0034 652629 247, e-mail: ingenieria.agenciaenergia@ayto-murcia.es
}

\begin{abstract}
This study is focused on assessing the real performance of a solar thermal system under current Spanish regulation compliance using TRNSYS. The effects on consumption pattern and occupancy rate based on the relationship between the seasonal profiles and the asynchronism between production and demand of a solar thermal system is investigated. Besides, the effect of various parameters such as mass flow rate through collector and initial water temperature is analyzed. The results of the simulation show that the system performance is affected strongly by the change of demand profile, primary mass flow rate and initial water temperature. Furthermore, the research shows that current Spanish regulations do not guarantee the safety of use in such systems because overheating problems, caused by applying some combinations of the above parameters, appear during summer period.
\end{abstract}

\section{Key words}

Solar thermal system, TRNSYS, energetic analysis, overheating problems, consumption patterns, Spanish regulation, CTE DB HE4.

\section{Introduction}

With the approval of the Technical Building Code[1] (CTE, Codigo Tecnico de la Edificacion) in 2006, Spain became one of the countries with the most advanced solar legislation in the world. The CTE has been the most significant reform of the Spanish building sector for decades, covering security of the buildings structure, fire safety, other safety and health issues, sustainability and energy efficiency of the buildings. The latter part goes far beyond the minimal level of implementation of the EC Directive on the Energy Performance of Buildings and includes an obligation to cover $30-70 \%$ of the Domestic Hot Water (DHW) demand with solar thermal energy.

Because CTE is quite restrictive it does not leave much leeway for maneuver during the design and sizing of a SHW system. However, it is possible that under some combination of inputs (e.g. asynchronous consumption patterns and low occupancy rate) the system can suffer some overheating problems. To conduct this study the next steps has been followed: sizing a facility as CTE, define the demand profile, simulate the installation by entering the appropriate parametric variations and analyze the results.

\section{SHW system sizing according to Spanish regulations}

The solar thermal part of the CTE (DB HE4) applies to any kind of new buildings, independent of their use, and to those undergoing a renovation. The most important parameter that determines the compliance with the solar regulation is the solar factor.

The required solar fraction of the hot water demand varies from $30-70 \%$, depending on following parameters:

1) The assumed volume of HW demand: the larger the consumption, the higher the required solar fraction. This is due to the fact that solar systems are more effective if the heat load (i.e. the consumption) is higher. The CTE defines the consumption according to the building type.

2) The kind of back-up energy: in case of electricity, the required solar fraction is higher than in case of gas or oil back up.

3) The level of solar radiation available. The CTE divides Spain in five climatic zones and allocates each province, or in some cases smaller territorial units, to one of these zones.

Having determined the required solar contribution, the CTE contains prescriptions on the method to calculate the system performance and on the required maintenance procedures. However, Spanish regulation does not specify how to perform this calculation, leaving the calculation method at the discretion of the designer. F-Chart [2,3] is the most commonly used method for Spanish engineers in SHW systems design. It is a static method based on 
correlations developed in last century. The main advantage of this method is that it is relatively simple and can be easily incorporated into a spread sheet.

Despite this, it has some limitations, among the most important:

1) It is valid only for a constant consumption pattern

2) The collector second-order heat loss coefficient is not incorporated

3) It does not envision neither the collector or solar tank could reach their maximum temperature nor a variation in primary mass flow rate

4) The distribution circuit is not included

The CTE defines a number of technical requirements on the components, design and installation of the solar thermal system, including sections on the solar collector and its components, the working fluid, the storage systems, the hydraulic circuit, the controllers and the conventional auxiliary system.

These technical requirements cover dozens of pages and cannot be discussed in detail here. This high level of detail originates from the wish of the government to assure the quality and the proper working of the solar systems and to reduce the possibility of different interpretations, thus creating more legal clarity. To assess the performance of a solar thermal system under current Spanish regulation compliance, a building with high variation in hot water demand, such the hotel described in Table I, is considered. The number of beds and the hotel category are extracted from Statistical Institute of Catalonia IDESCAT. Most common values from Barcelona city are used.

The following table lists the design data requested by the CTE:

Table I. - Characteristics of the installation

\begin{tabular}{|l|c|l|}
\hline & VALUE & \multicolumn{1}{|c|}{ COMMENTS } \\
\hline Bulding type & $* * *$ Hotel & - \\
\hline Location & Barcelona & Climatic zone II \\
\hline Number of beds & 186 & beds \\
\hline HW consumption & 55 & $1 /$ bed \\
\hline Daily HW consumption & 10.230 & $1 /$ day \\
\hline Collector area & 2.32 & $\mathrm{~m}^{2}$ \\
\hline Tilt angle $\beta$ & $41^{\circ}$ & - \\
\hline Azimuth angle $\alpha$ & $0^{\circ} \mathrm{S}$ & - \\
\hline Collector type & Flat plate & Vitosol $200 \mathrm{~F}$ \\
\hline Optical efficiency $\eta$ & 0.846 & - \\
\hline $1^{\text {st }}$ order heat loss coef. & 3.263 & $\mathrm{~W} / \mathrm{m}^{2} \mathrm{~K}$ \\
\hline $2^{\text {nd }}$ order heat loss coef. & 0.0230 & $\mathrm{~W} / \mathrm{m}^{2} \mathrm{~K}^{2}$ \\
\hline Glycol-water mix & 20 & $\%$ \\
\hline Back up energy & gas & - \\
\hline Solar fraction required & 70 & $\%$ \\
\hline Primary mass flow rate & 5.5 to 9.2 & $\mathrm{~m}^{3} / \mathrm{h} \mathrm{CTE}$ \\
\hline
\end{tabular}

For Barcelona, the inlet water temperature varies from 8$13^{\circ} \mathrm{C}$ in the winter and $13-16^{\circ} \mathrm{C}$ in the summer. Otherwise, the ambient temperature varies from $11^{\circ} \mathrm{C}$ to $26^{\circ} \mathrm{C}$. The monthly mean temperatures for Barcelona urban area are presented in Figure I. The temperatures used in F-Chart method are extracted from Institute for the Diversification and Saving of Energy (IDAE) in its publication "Pliego de Condiciones Técnicas de Instalaciones de baja temperatura".

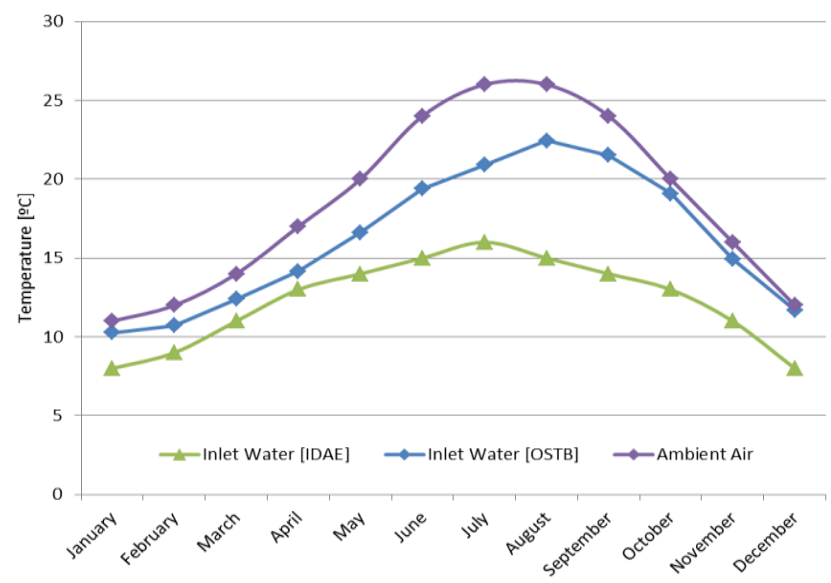

Fig. 1. Inlet water and ambient temperature for Barcelona.

The hot water consumption depends on the season of the year and the occupancy. In tourist residential installations should take into account the partial occupations consequence of the variability of the occupation. The occupancy rate values shown in Fig 2 are extracted from National Institute of Statistics (INE) in its last Hotel Occupancy Survey. Averaged values from Barcelona city are used.

The solar contribution $f$ determines the compliance with the Spanish regulation DB HE4. It should be as close as possible to the minimum solar fraction marked on CTE. The table II shows the main results extracted from F-Chart sheet.

Table II. - F-Chart results

\begin{tabular}{|l|c|l|}
\hline Number of collectors & 55 & \\
\hline Collector area & 127.6 & $\mathrm{~m}^{2}$ \\
\hline Solar fraction & 73 & $\%$ \\
\hline Water tank volume & $2 \times 5000$ & Liters \\
\hline
\end{tabular}

The monthly solar factor obtained and the occupancy rates used are shown in Fig 2.

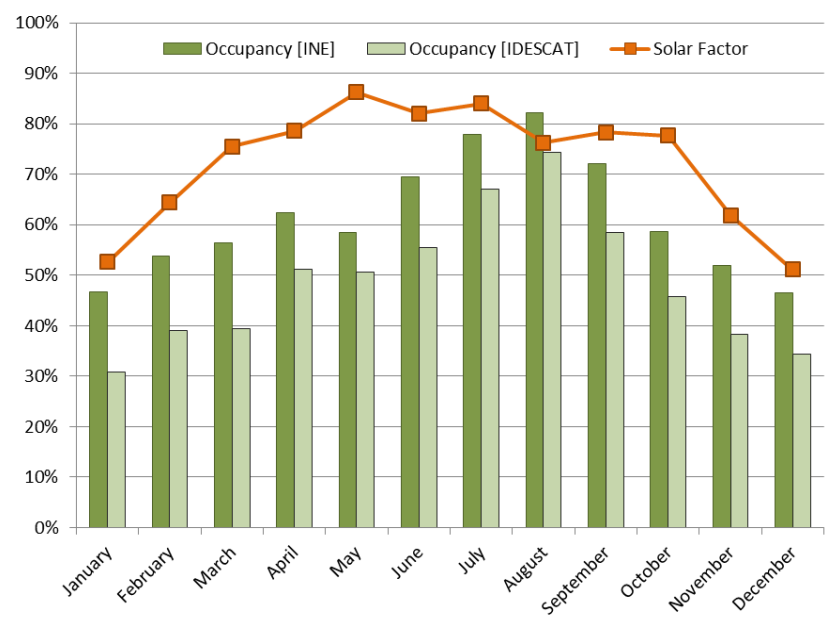

Fig. 2. Solar fraction and occupancy rates. 
In case that in any month the solar contribution exceeds $110 \%$ of the energy demand or $100 \%$ more than three consecutive months, CTE obliges to install an overheating protection system (e.g. coverage of the collector field, emptied of the primary circuit or incorporate a heat sink). As can be seen in Fig 2 the installation of this protection is not necessary.

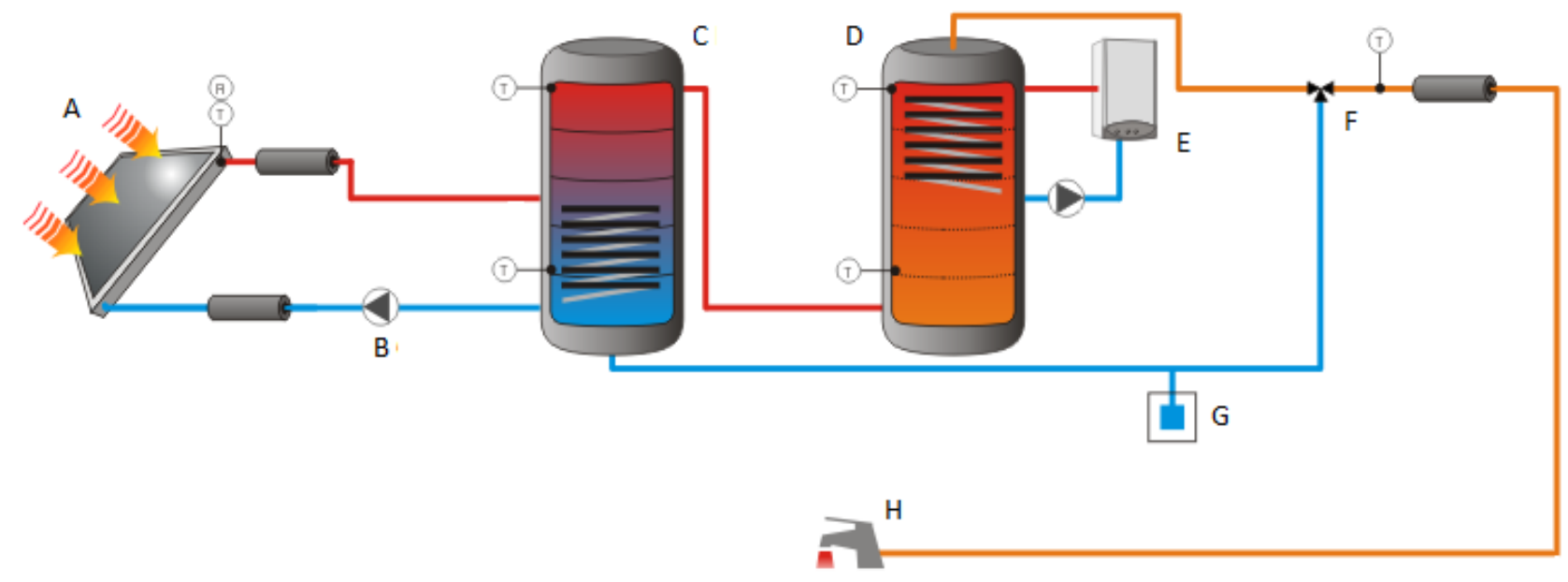

Fig. 3. Scheme of the installation.

\section{Water heating load}

To test the influence of HW consumption pattern in SHW systems, appropriate design information of the installation such as hotel consumption pattern or near inlet water temperature data are needed.

In the previous SHW system design, constant hot water mass flow rate consumption is considered because of $\mathrm{F}$ Chart method. However, the hot water consumption depends on the time of the day and the work developed in the building. Therefore an accurate demand profile is used. The Fig 3 shows the hotel daily hot water demand profile used, extracted from monitoring values [4].

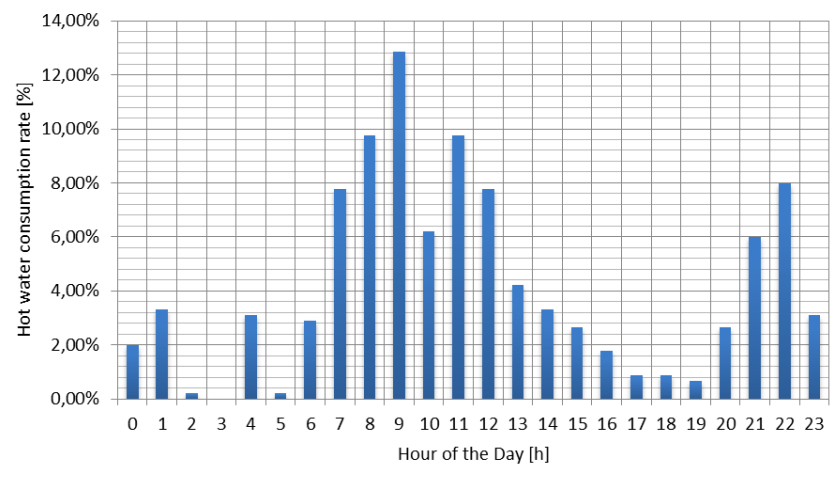

Fig. 4. Hotel hot water consumption pattern.

On the other hand latest occupancy rates obtained from Statistical Institute of Catalonia IDESCAT also are used. The monthly occupancy rates for Barcelona hotels are shown in Fig 2.

Also the effect of primary mass flow rate is investigated [5]. CTE allows a variation between 1.21/s and 21/s for every $100 \mathrm{~m}^{2}$ of solar collection. It means that, in this case, the mass flow rate could be set up between $5500 \mathrm{~kg} / \mathrm{h}$ and $9200 \mathrm{~kg} / \mathrm{h}$. Depending on the case the worst value is used.
Finally the inlet water temperature obtained from Barcelona Solar Ordinance OSTB, shown in Fig 1, is considered.

\section{Dynamic simulation of the system behaviour}

Numerical simulations were carried out using TRNSYS software [6,7], one of the most important building energy simulation software, that is used by engineers and researchers around the world to validate new energy concepts, from simple solar domestic hot water systems to the design and simulation of buildings and their equipment, including control strategies, occupant behavior, alternative energy systems (wind, solar, photovoltaic, hydrogen systems), etc.

A simple scheme of the hot water system is presented in Figure 4. While sun shines on the solar collectors (A) the pump of the primary closed circuit (B) transfers the heat from panels to the primary water tank (C). The stored water flows to the auxiliary tank (D) where an auxiliary heater $(\mathrm{E})$ heats the stored water to $60^{\circ} \mathrm{C}$ when no sun is available. The system produces $102301 /$ day of sanitary hot water at $60^{\circ} \mathrm{C}$ for hotel consumption $(\mathrm{H})$. The mixing valve $(\mathrm{F})$ reduces the temperature of stored water to $45^{\circ} \mathrm{C}$ mixing it with the inlet water $(\mathrm{G})$.

\section{Results and discussion}

Fig. 5 and 6 show the asynchrony between hot water production and demand in August and January respectively. It can be observed that in both cases the energy harvested does not correspond with the demand profile. That is the reason why the use of storage tank is necessary. With storage tanks the efficiency of the SHW system increase and the hot water drains out of solar time could be satisfied. 


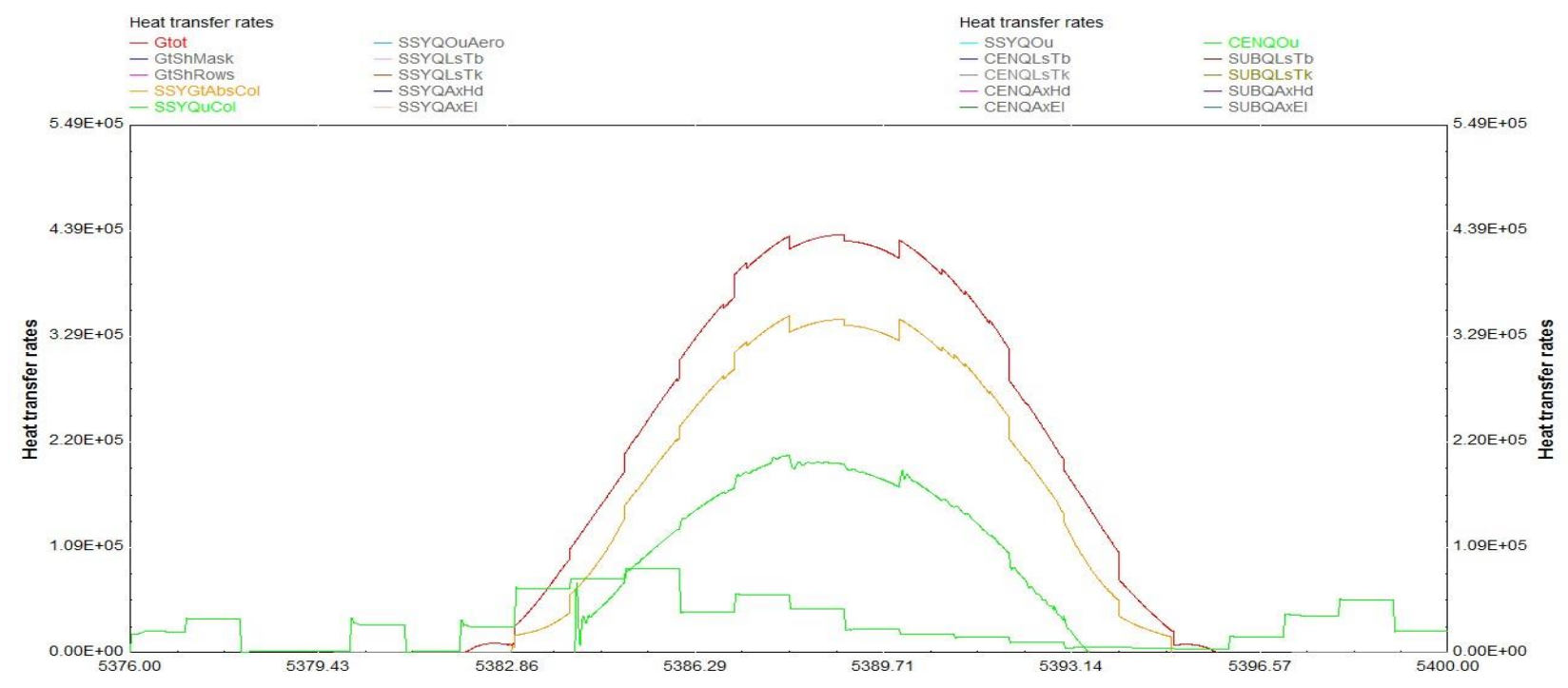

Fig. 5. Heat transfer rates extracted from TRNSYS simulation. August. Mass flow rate set up to 5500kg/h.

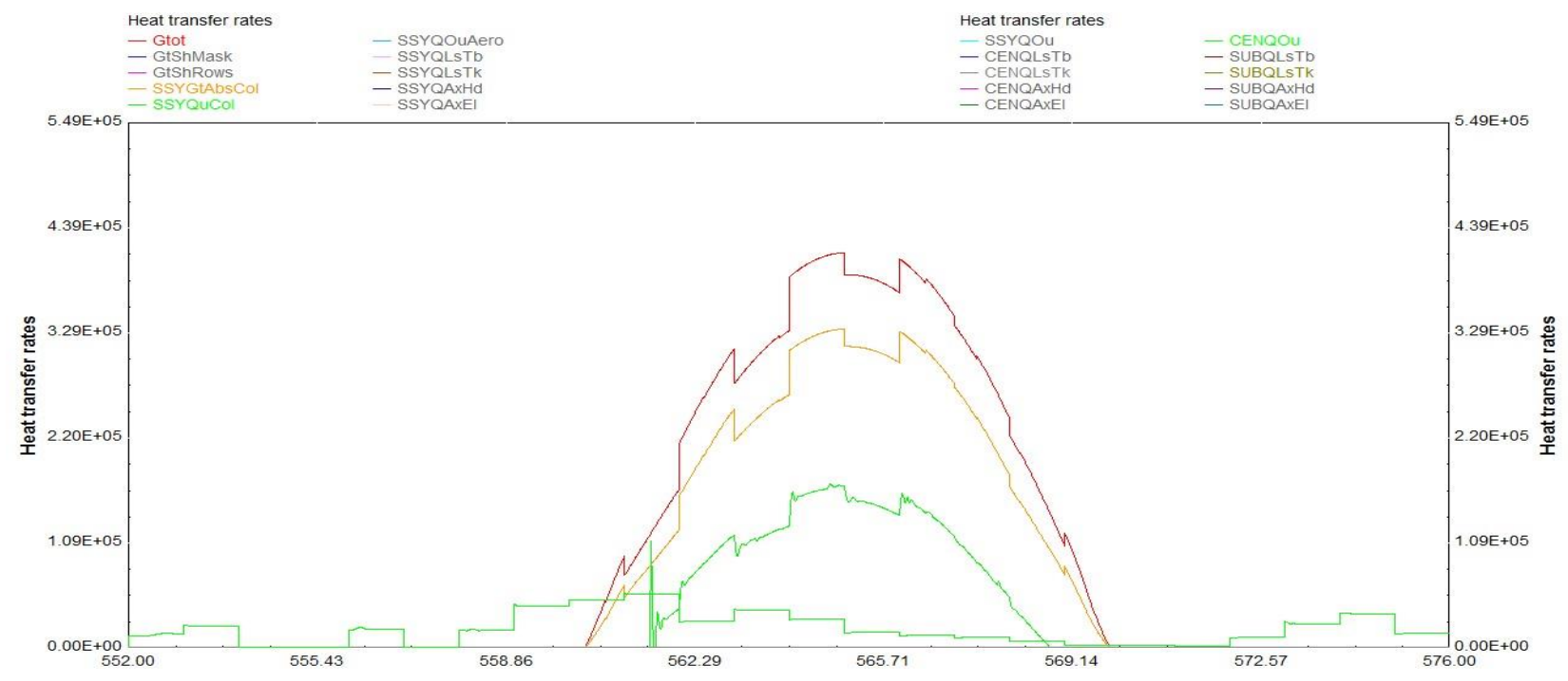

Fig. 6. Heat transfer rates extracted from TRNSYS simulation. January. Primary mass flow rate set up to $5500 \mathrm{~kg} / \mathrm{h}$.

However, hot water storage without regularly consumptions can produce high primary circuit and high primary storage tank temperatures. The maximum recommended temperature is $120^{\circ} \mathrm{C}$ for primary circuit and $90^{\circ} \mathrm{C}$ for storage tank.

Fig. 7 shows the heat balance of the SHW system. It can be observed that in June, July and August the solar production is slightly higher than monthly energy demand. This energy excess, which is not contemplated in previous F-Chart sizing, can lead to overheating problems. It must be remembered that in this cases CTE would oblige to include an overheating protection system. In addition, the average solar factor extracted from the simulation is $89 \%$, $21.9 \%$ higher than $73 \%$ obtained from F-Chart.

Fig. 8 presents the hot water production during the first week of September. It can be observed that the solar collector outlet temperature can reach $120^{\circ} \mathrm{C}$ when the primary mass flow rate is set up to $7300 \mathrm{~kg} / \mathrm{h}$.
Moreover, as shown in Fig. 9, on certain days of summer temperatures above $90^{\circ} \mathrm{C}$ can be achieved in primary tank.

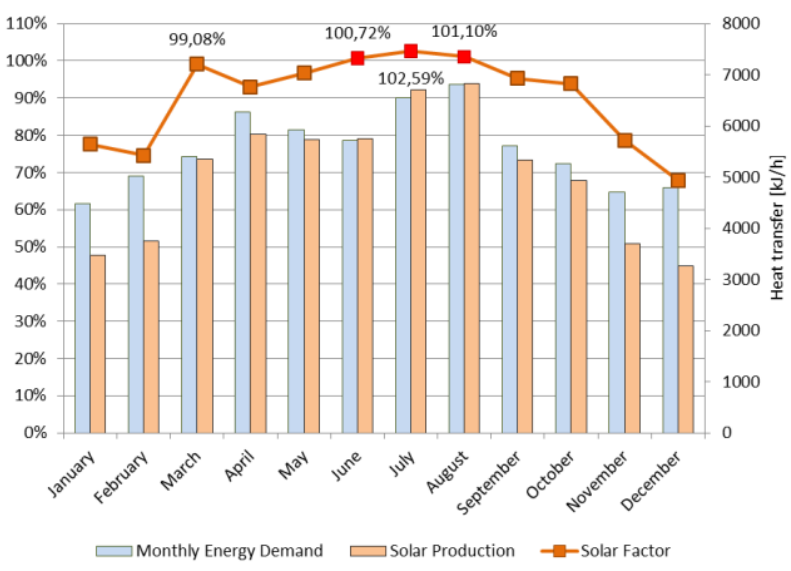

Fig. 7. Hotel SHW system heat balance. Mass flow rate set up to $5500 \mathrm{~kg} / \mathrm{h}$. 


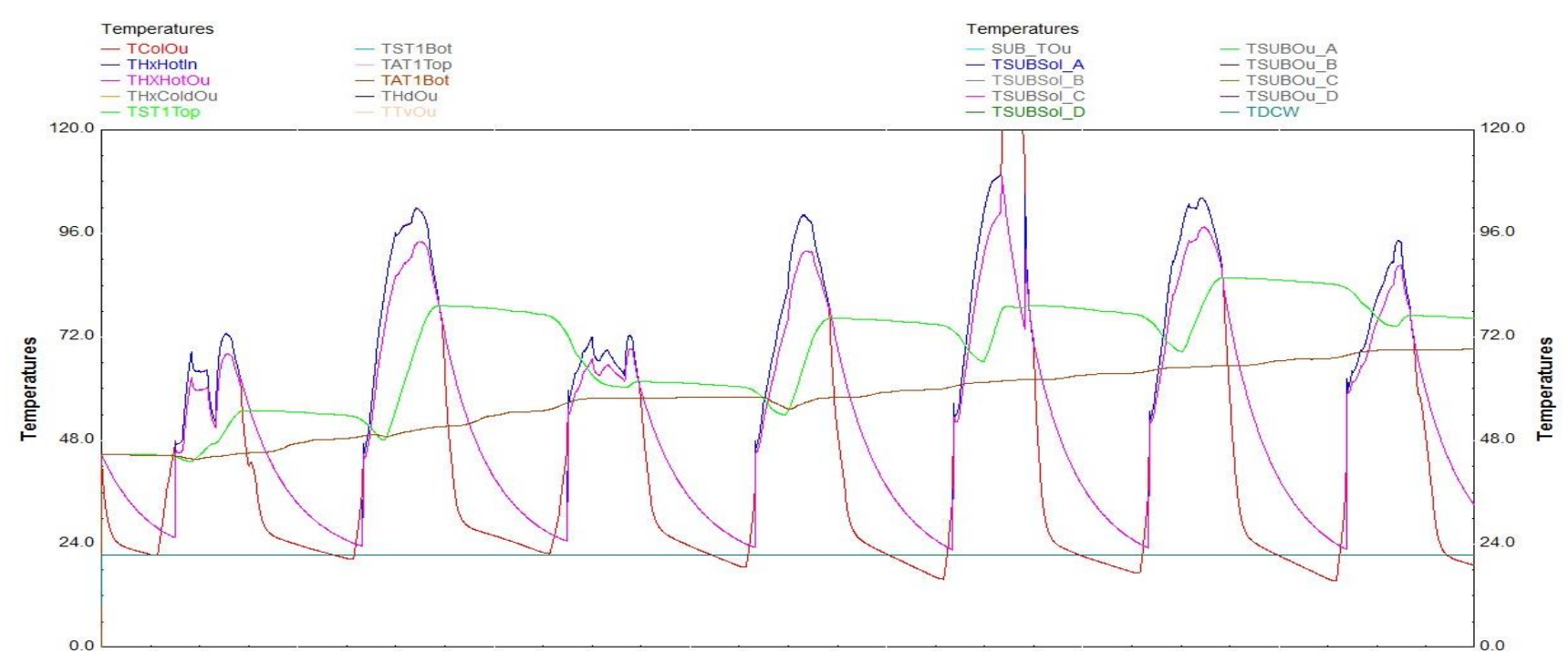

Fig. 8. Hot water production during the first week of September. Primary mass flow rate set up at $7300 \mathrm{~kg} / \mathrm{h}$.
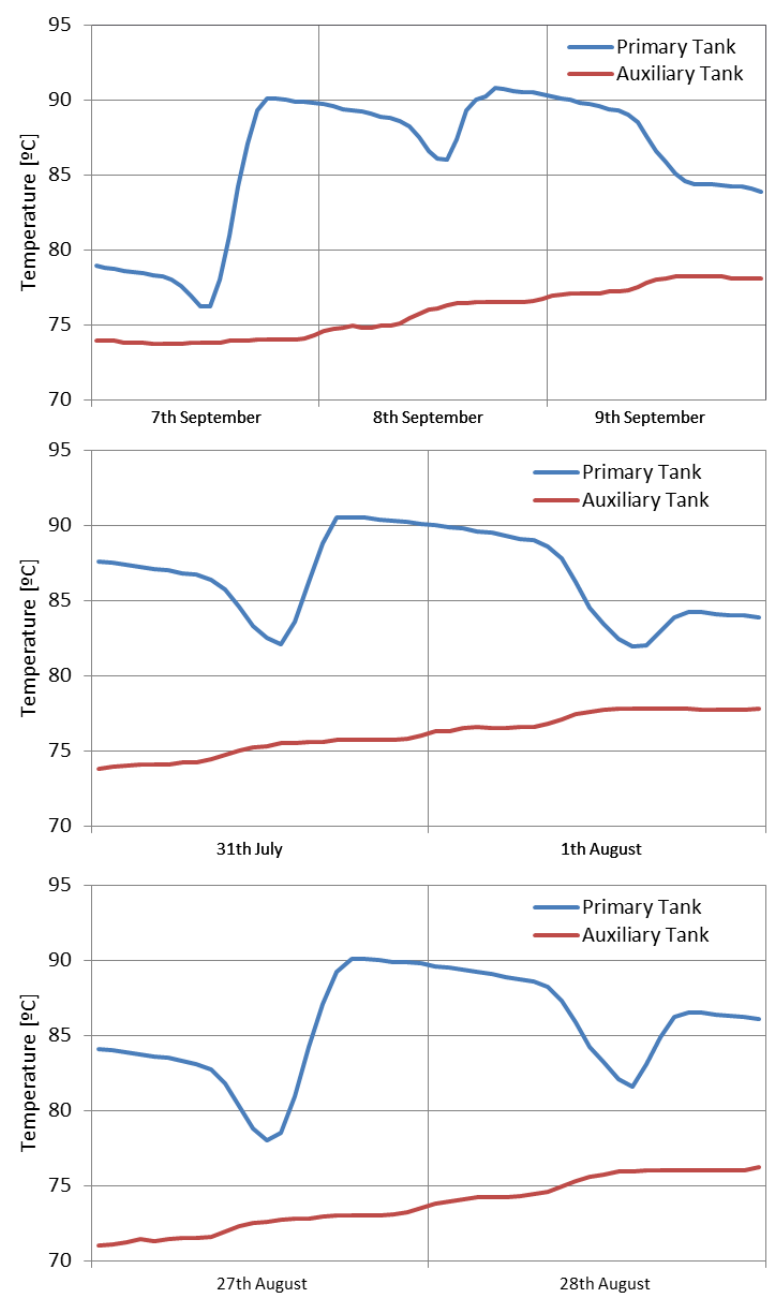

Fig. 9. Primary and auxiliary tank temperature. Primary mass flow rate set up to $5500 \mathrm{~kg} / \mathrm{h}$.

\section{Conclusions}

In this study, a transient thermal simulation is developed to assess the real performance of a solar thermal system under current Spanish regulation compliance using TRNSYS.
The results of the simulation show that in summer, when the incident solar radiation is higher, there is a less pronounced asynchrony between demand and solar production than in winter. For this reason the majority of overheating problems occurs in this period.

Both, the demand profile and the occupancy level, directly affects to the solar contribution. Also, low mass flow rate through collectors can have the same effects. In cases where the demand profile is markedly asynchronous and/or occupancy is lower than expected, a significant increase in the solar factor is observed (i.e. months with solar factors greater than $100 \%$ ) which can cause seriously overheating problems. These problems can be traduced into primary circuit temperatures above $120^{\circ} \mathrm{C}$ (Fig. 8) and/or primary storage temperatures above $90^{\circ} \mathrm{C}$ (Fig. 9).

Because of the variability and unpredictability of these profiles, Spanish regulation should be amended to include the requirement to incorporate overheating protection systems in large SHW installations.

\section{References}

[1] Código Técnico de la Edificación. Ministerio de la Vivienda. Real Decreto 314/2006, de 17 de marzo de 2006.

[2] Beckman W.A., Klein S.A. Duffie J.A., Solar Heating Design by the f-chart Method, Wiley-Interscience, New York, 1977.

[3] Klein S.A., Beckman W.A. F-Chart User's Manual, University of Wisconsin, 2005.

[4] E. Joseph, Monitoring and modeling hot water consumption in hotels for solar thermal water heating system optimization, Appalachian State University, 2011.

[5] Furbo S, Shah LJ. Optimum solar collector fluid flow rates. Department of Buildings and Energy, Technical University of Denmark, proceedings of Eurosun 1996.

[6] S.A. Klein, et al., TRNSYS 16: A Transient System Simulation Program, University of Wisconsin USA (2006).

[7] A. Hobbi, et al., Optimal design of a forced circulation solar water heating system for a residential unit in cold climate using TRNSYS, Solar Energy 83 (2009) pp. 700-714. 